\title{
LA HUELLA DE GUGLIELMO DELLA PORTA EN OBRAS DE MARFIL EN ESPAÑA. LOS TALLERES ROMANO Y DEL BUEN RETIRO DE LOS POZZO Y UN INCISO SOBRE EL DE SAINT CLAUDE EN EL FRANCO CONDADO
}

\author{
Margarita M. Estella \\ Consejo Superior de Investigaciones Científicas, Madrid
}

\begin{abstract}
Se analiza el reflejo de las composiciones de Guglielmo Della Porta en diferentes obras de marfil localizadas en España de distinta cronología y su posible adscripción a sus conocidos discípulos o contemporáneos de este artista que trabajaron el marfil, como Jacob Cornelisz Cobaert, conocido como Cope, o Nicolás Piper de Arras también llamado Pippi. Conocida la difusión de los modelos de Guglielmo en el taller de Giovanni Battista del Pozzo en el siglo XVIII, padre de Andrea del Pozzo el Director del taller español de Marfiles del Buen Retiro, se analizó en este contexto otras obras. Se incluye el estudio de dos pequeños relieves de colección alicantina que pertenecieron a un Via Crucis conservado en Boulogne sur Mer, de sugerida atribución a un taller de Saint Claude, pues por su estilo pueden confundirse con las del Buen Retiro.

Palabras clave: Escultura en marfil; Guglielmo Della Porta; Jacob Cornelisz Cobaert; Cope; Nicolás Piper o Nicolás de Arras; Pippi; Giovanni Battista y Andrea Pozzo; los Rosset; Coleccionismo en España.
\end{abstract}

\section{THE TRACE OF GUGLIELMO DELLA PORTA ON IVORY WORKS IN SPAIN. THE ROMAN AND BUEN RETIRO WORKSHOPS OF THE POZZOS AND AN OBSERVATION ON THAT OF SAINT CLAUDE IN THE FRANCHE COMTÉ}

The author analyzes the reverberations of the compositions of Guglielmo Della Porta on different ivory works located in Spain of varying chronology and their possible attributions to his known disciplues or contemporaries who worked in ivory, such as Jacob Cornelisz Cobaert, called Cope, or Nicolás Piper de Arras called Pippi. The diffusion of Guglielmo's models in the workshop of Giovanni Battista del Pozzo during the $18^{\text {th }}$ century is known. Giovanni was the father of Andrea del Pozzo, Director of the Spanish ivory workshop in the Buen Retiro, and so other works are analyzed in this context. Also included in this study are two small reliefs in a collection in Alicante, which originally belonged to a Via Crucis preserved in Boulogne sur Mer, here attributed to a Saint Claude workshop, given that stylistically they can be confused with Buen Retiro creations.

Key words: Ivory sculpture; Guglielmo Della Porta; Jacob Cornelisz Cobaert; Cope; Nicolás Piper or Nicolás de Arras; Pippi; Giovanni Battista \& Andrea Pozzo; The Rosset; Collecting in Spain. 


\section{La influencia de Guglielmo Della Porta en la pequeña escultura}

La figura de Guglielmo Della Porta domina el panorama del desarrollo escultórico de Roma en el último cuarto del siglo XVI. La difusión de su obra en el arte europeo ha sido destacada por diversos autores a la que ahora pueden añadirse algunos ecos de su arte detectados en las pequeñas obras de marfil de su época y posteriores.

El arte de la eboraria aparece en principio ajeno a su quehacer pero se sabe que a más del importante papel que desempeña en su taller Jacob Cornelisz Cobaert, conocido con el nombre de Cope, se conoce la actividad que desarrolla en Roma por los mismos años Nicolás Pippi (Piper) también conocido como Nicolás de Arras ambos, de procedencia flamenca y hábiles en la talla del marfil como atestiguan las fuentes antiguas, sea Baglione o más posteriormente Bertolotti ${ }^{1}$.

\section{El crucifijo de colección riojana}

Entre las obras que se considera reflejan la influencia del arte de Guglielmo se recuerda ahora un interesante Crucifijo de marfil, de colección particular riojana, de 37 x $36 \mathrm{~cm}$ que en su día se clasificó como obra italiana de hacia 1600 quizás por dibujo miguelangelesco y en cierto modo reflejo del Cristo de Cellini conservado en El Escorial ${ }^{2}$, por su desnudez (figs. 1 y 2).

Con la cabeza inclinada sobre el pecho, algo ladeada a la derecha, enmarca su rostro con cabellera retirada hacia atrás en airosos rizos a la derecha, cayendo en ondas suaves sobre el hombro a la izquierda. Sus ojos cerrados, la nariz levemente aguileña, rodea su boca, de labio grueso inferior hundido en su centro, con bigote de lacias guías que se unen a los lados con tupida barba rizosa trabajada a trépano. De proporciones esbeltas eleva su flaco tórax, con la herida de la lanza al lado izquierdo en actitud de esfuerzo sobre su vientre hundido que destaca los genitales entre sus flacos y largos muslos en relación a las pantorrillas. De brazos largos ligeramente elevados sobre la horizontal curva los dedos de sus manos sobre la marca de los clavos, perdidos, de sus palmas.

Al dorso su cabellera se ciñe al cráneo en ondas que se abren en rizos en melena sobre la espalda que agudiza la delgadez exagerada de toda su anatomía salvo al dorso de sus pantorrillas que destaca los músculos en tensión debido al peso del cuerpo.

Revisando de nuevo el modelo italiano en el que pudo inspirarse se ha advertido que en conjunto este Cristo de marfil presenta recuerdos claros de los famosos dibujos de Guglielmo Della Porta e incluso detalles característicos de alguna de sus obras conocidas. Su conjunto responde a la composición que adopta alguno de los dibujos de sus Crucificados como el representado en el diseño de un Calvario o el del preparatorio del grupo de Cristo a la columna que aparece desnudo, sin el perizoma ${ }^{3}$.

Muy recientemente en la subasta que Sotheby celebró en Londres, se presentó un interesante Crucificado en bronce dorado ${ }^{4}$ cuyas características aparecen próximas al ejemplar que se estudia, sobre todo las referentes a su anatomía y que también, curiosamente, se representa desnudo. Son similares sus esbeltas proporciones pero difiere la factura de los cabellos y los rasgos de su rostro pero en todo caso es una obra poco común de este tipo de Crucificados manieristas sobre la que convendrá insistir en el futuro. Atribuido a Jacopo Del Duca, según un modelo de Miguel Angel, se clasifica como obra italiana de taller romano de finales del siglo XVI.

\footnotetext{
${ }^{1}$ Baglione, 1642, 100-101. Bertolotti, 1880, 381. Bertolotti, 1881, 127. 138.

${ }^{2}$ Estella, 1984, I fgs. 93 y 95; II cat. $n^{\circ} 80$.

${ }^{3}$ Gramberg, 1964, 76 y 103.

${ }^{4}$ Sotheby's julio 2014, Lot 85. Agradezco a Almudena Pérez de Tudela la noticia.
} 


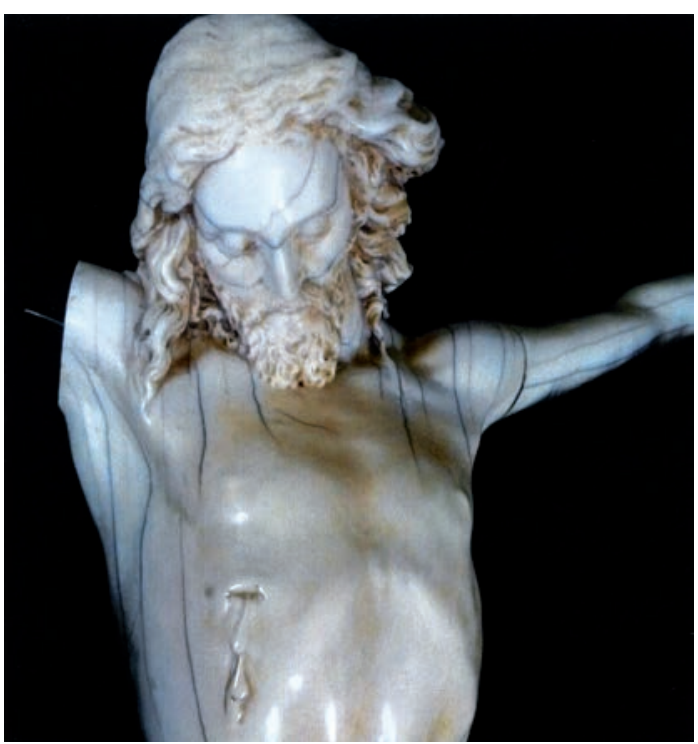

Fig. 1. Crucificado, marfil, detalle. Logroño, colección particular.

Fig. 2. Crucificado, marfil, detalle. Logroño, colección particular.

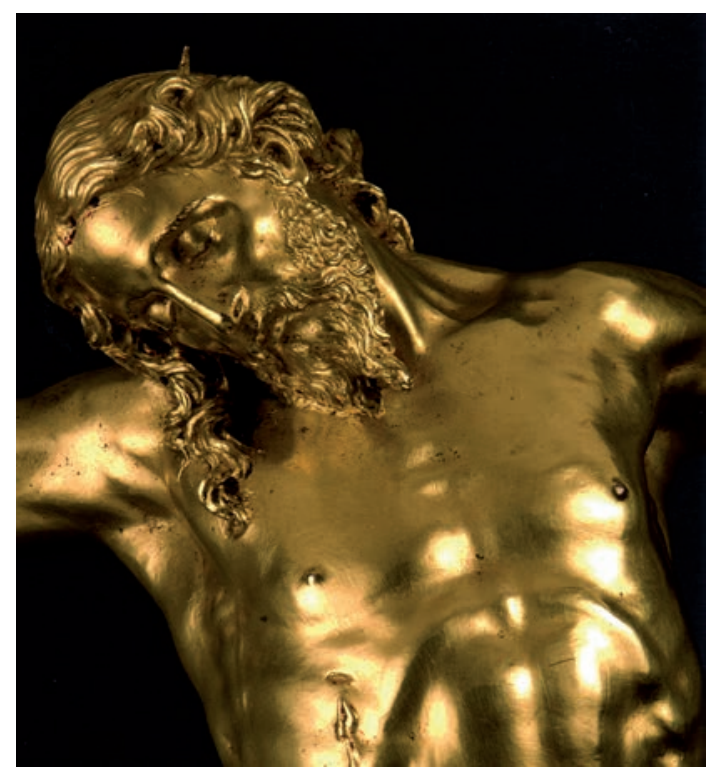

Fig. 3. Guglielmo Della Porta, Crucificado, bronce. Viena, colección particular (procede de mercado arte).

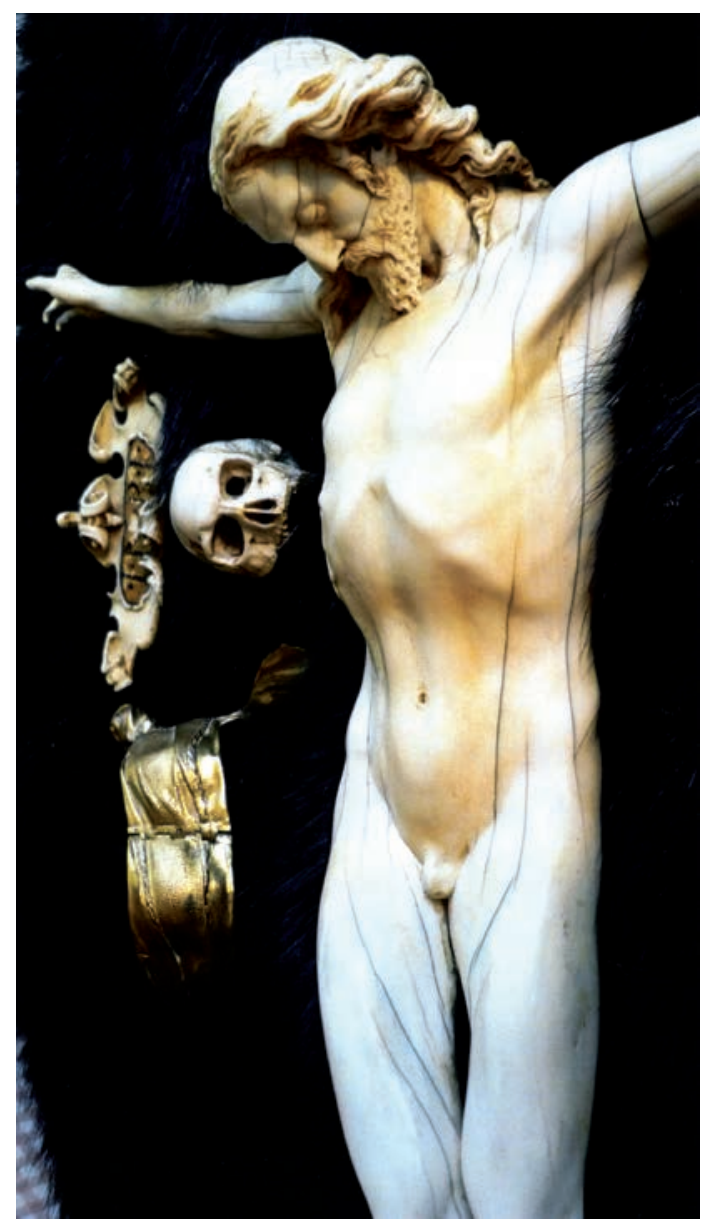

Es más claro su parecido con el Cristo de bronce que recientemente pasó por el comercio de $\operatorname{arte}^{5}$ (fig. 3). Repite el ángulo de inclinación de su cabeza, la disposición del cabe1lo, menos alborotado a la derecha que en el Cristo de marfil, del que repite su rizada barba a partir de los pabellones auriculares. Su anatomía es más cuidada, menos delgada pero también destaca los pectorales, el arco de las costillas sobre el vientre y el alargamiento de los muslos en relación con el resto de sus piernas pero no se conoce ningún ejemplar de Crucificado de este artista que se represente desnudo.

\footnotetext{
${ }^{5}$ Coppel, 2012, cat. 82-87.
}

Arch. esp. arte, LXXXVIII, 351, JULIO-SEPTIEMBRE 2015, 243-262

ISSN: 0004-0428, eISSN: 1988-8511, doi: 10.3989/aearte.2015.15 
Aunque el estudio comparativo no es definitivo más teniendo en cuenta la difusión de este tipo de Cristo moribundo y la delicadeza de la talla de los ejemplares de Guglielmo que acaricia cada detalle en contraste con la cierta rudeza del Cristo de marfil, pero si puede considerarse a éste en el círculo de influencia del arte del gran escultor. El análisis que a continuación se hace de otras obras de la pequeña escultura en marfil que relacionamos con Della Porta apoya la sugerencia.

\section{El relieve del Descendimiento de la Cruz, de la colección Duquesa de Parcent}

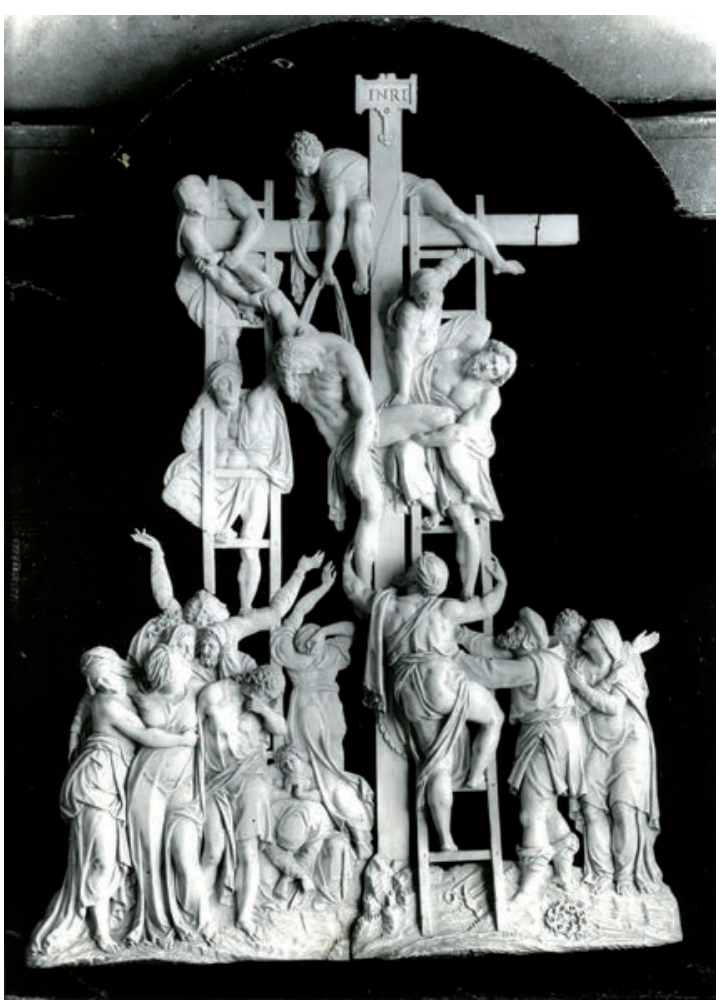

Fig. 4. Niccoló Pippi. Descendimiento, marfil. Ronda (Málaga), Duquesa de Parcent (Hoy en localización desconocida).

Las dudas surgidas en el anterior estudio aconsejó la revisión de otras obras de marfil en España que en su día se consideraron obras de esta cronología y escuela romana. Entre las de más clara adscripción destacaba un precioso relieve del Descendimiento de la cruz (fig. 4) que estudiamos en su día como obra italiana de finales del siglo XVI y a la que se relacionó con un ejemplar muy similar conservado en la Biblioteca Apostólica del Vaticano, estudiado por Morey ${ }^{6}$.

Ambos relieves se consideraban obras anónimas hasta los estudios recientes de Eike Schmidt y Economopoulos, interesados por desvelar la obra en marfil del citado Pippi, al que relaciona el segundo autor con Cope ${ }^{7}$.

Entre las escasas noticias que se tenían sobre ambos escultores flamencos que trabajan en Roma en la segunda mitad del siglo $\mathrm{XVI}$ interesaron en especial las que los presentaban como hábiles en la talla de pequeñas obras en marfil, pero no se había localizado ninguna de las que les atribuían fuentes clásicas como Baglione o Bertolotti ${ }^{8}$. La bibliografía moderna ha añadido una serie de noticias sobre sus vidas y obras que han permitido presentar un panorama más concreto sobre su actividad en este campo y sobre la difusión en la eboraria de los modelos del maestro hasta fechas avanzadas del siglo XVIII.

De Nicoló Piper de Arras, llamado en Italia Niccoló Pippi se conocía su actividad como escultor en otros materiales y como se ha dicho y a partir de los primeros años del siglo XX se le dedican diversos estudios que recogidos y ampliados por Economopoulos nos presentan su entera y muy

\footnotetext{
${ }^{6}$ Morey, 1936, no 117, lám. XXXIII. Estella, 1984, cat. 8, fig. 5

${ }^{7}$ Schmidt, 2008 e Idem, 2012. Economopoulo S., 2013

${ }^{8}$ Baglione y Bertolotti, cit. en nota 1 .
} 
completa biografía. Se conoce por ejemplo que el propio Granvela lo compara con Giambologna y lo recomienda para la obra de El Escorial. También se menciona el Crucifijo de marfil que añade a su obra en piedra para la capilla Sixtina de Santa Maria Maggiore y otros dos cuyo pago se consigna en 1571 pero y sobre todo, para el objeto de este estudio, se menciona la colaboración de Jacob Cornelisz Cobaert, Coppe, el fiel ayudante de Guglielmo Della Porta y posiblemente también la del propio Giambologna, en el taller del Pippi que en cierto modo, por su polifacética actividad, puede compararse al significado que tuvo el taller del Frate del Piombo, cuando muere el lombardo. Así por ejemplo se recuerda la coincidencia del Cope, del que más adelante se hablará, con Pippi en las obras para el cardenal Contarelli y el encargo que Cope recibe en 1596, de unas pequeñas obras en marfil ${ }^{9}$.

Unos años antes que el trabajo mencionado de Economopoulos, Eike Schmidt en un intenso trabajo de investigación, localizó en los Inventarios mediceos la descripción de varios relieves de marfil que representaban el Descendimiento de la Cruz, entre los cuales destacaba la siguiente: «Un quadretto d'una dipositione di Crocie di Christo d'avorio con fondo di pietra nera a modo de cammeo con quatttordoci figure fatto su disegno di Daniello da Volterra senza ornamento e largo bracci $2 / 3$ e alto braccia $1 \mathrm{o} / 4 \ldots$ avuto da maestro Niccoló Pipe fiammingho adi 13 di maggio 1579», describiendo el elaborado marco de plata que lo cobija y consignando en página adjunta al inventario que fuese «consegnato al signor Giovanni Valenzuela che Sua Signoria Illustrisima« -el Cardenal Fernando de Médicis- «lo mando a presentare al Illustrissimo Eccelentissimo signor priore Don Ernando de Toledo viceré di Catalogna $\ll^{10}$.

El Inventario del año de 1589 describe también «Un quadro con cornice de bronzo dorato con fondo di cristallo nero, attacatovi sopra la sconficcazione di Nostro Signore di basso rilievo d ' avorio disegno di Michelangelo di braccia 2/3 qlto largo braccia $03 . . . »$.

La descripción de estos dos relieves y de otros varios consignados asimismo en los citados Inventarios sugirió al autor la adscripción al mismo artista, Pippi, citado en el de 1579, de tres relieves de marfil del mismo tema conservados uno en el Museo Degli Argenti de Florencia, del que puede seguirse su rastro a través del tiempo en los documentos citados, otro segundo en La Biblioteca Apostólica del Vaticano y el tercero no localizado hasta la fecha y conocido únicamente a través de una buena fotografía que dimos en su día en nuestros estudios y en la que se consignaba como propiedad de la Duquesa de Parcent. Al solo conocerse por fotografía ya que hasta la fecha no ha sido localizado, no puede comprobarse si pudiera ser el relieve del Pippi enviado a España, a D. Hernando de Toledo ${ }^{11}$.

Se sabía que don Hernando de Toledo era hijo natural del tercer Duque de Alba al que acompañó en muchas de sus empresas militares y se tienen noticias de su rica colección artística, parte de cuya almoneda fue adquirida por Felipe II según consta en la relación de las Entregas al Escorial incluidos muchos de los cuadros del Bosco de las colecciones reales que le pertenecieron. Las noticias que recoge esta relación al parecer no hacen referencia a ninguna obra de marfil y hasta la fecha no sabemos si el relieve se conserva en la colección ${ }^{12}$. El estudio en su conjunto presentaba el problema que en los últimos años del siglo XIX el entonces Conde de Parcent, don Fernando de la Cerda, casó sucesivamente con $\mathrm{D}^{\mathrm{a}}$ Josefa Ugarte Barrientos y a su muerte con $\mathrm{D}^{\mathrm{a}}$ Trinidad de Scholtz, ambas malagueñas y destacado interés por las bellas artes ${ }^{13}$. El hijo de las primeras nupcias murió y el título pasó al sobrino don Florencio Granzow, padre del recién fallecido Duque de Parcent. No hubo descendencia de su matrimonio con $\mathrm{D}^{\mathrm{a}}$ Trinidad Scholtz de la que se sabe de

\footnotetext{
${ }^{9}$ Economopoulos, 2013, cap. I, 2 y p. 30, notas 90, 91 y 92; p.38, nota 144; p. 49, nota 177, p. 52, nota 190 y p. 85 nota 343

${ }^{10}$ Schmidt, 2008, 158-183. Schmidt, 2012, 30-33, nota 64.

${ }^{11}$ The Vatican Collections, 1983, cat. 53. Estella, 1984, cit. en 6.

${ }^{12}$ Pérez De Tudela, 2001. De nuevo agradezco a la autora esta noticia puntualizando que la recogió de Zarco Cuevas.

${ }^{13}$ Ramos Frenda, mayo-agosto, 2009.
}

Arch. esp. arte, LXXXVIII, 351, JULIO-SEPTIEMBRE 2015, 243-262

ISSN: 0004-0428, eISSN: 1988-8511, doi: 10.3989/aearte.2015.15 
su predilección por la villa de Ronda donde se ubicó el relieve de marfil y cuya hija casó con el Príncipe de Hohenlohe. Por lo dicho se ha hecho preciso indagar en ambas familias aunque las noticias apuntan a los Hohenlohe pero el catálogo de la almoneda del Quejigal, de su propiedad, no aportó datos sobre la obra de marfiil ${ }^{14}$.

No obstante esta fina obra del Pippi del Museo degli Argienti de Florencia, a la que se ajusta muy literalmente la localizada en Ronda, no recuerda al Crucificado procedente de la Rioja, quizás por ser una composición que se atiene muy exactamente a la interpretación por Volterra de una composición de Miguel Angel pero tampoco la conocida y amplia obra del Pippi en mármol y otros materiales nobles presenta detalles que permitan la comparación con el citado Cristo de marfil con reflejos del miguelangelismo de las obras de Guglielmo, en otra línea del seguido por este escultor flamenco. La abundante obra del Pippi en Roma recogida en extenso por Economopoulos como su magnífica estatua de Marco Antonio Colonna, II ${ }^{15} \mathrm{el} \mathrm{monumento} \mathrm{de} \mathrm{Karl} \mathrm{Friedrich} \mathrm{von}$ Kleve, en la iglesia de Santa María dell'Anima ${ }^{16}$ de los alemanes y los flamencos, y sus intervenciones en los sepulcros de los Papas Pio V y Sixto $\mathrm{V}^{17}$ que justifican la recomendación de Granvela para que trabaje en el Escorial, proponiéndole en la misma categoría que Giambologna ${ }^{18}$, no proporciona, no obstante, elementos que recuerden la obra de marfil a la que aludimos pero su relación con Cope permite incluirlo en el círculo de artistas que sin duda conocieron y recibieron la influencia de la obra de Guglielmo.

Precisamente Economopoulos se adentra en los antecedentes de este relieve del Descendimiento a través de los documentos que se contienen en el controvertido proceso del robo por Stefano Maderno del modelo del bajorrelieve de una Schiavellazione o Sconficcatione de Cristo, nombres con los que también se identifica el tema del Descendimiento de la Cruz, del taller de Piper, su maestro. Al parecer Piper acusa a Stefano no tanto del robo del modelo derivado de una composición de Miguel Angel sino de su autoría y posible futura utilización. El caso recuerda el que surgió a la muerte de Guglielmo Della Porta también relacionado con la desaparición de alguno de sus modelos extendiéndose el autor en el valor que en aquellos años se daba a estas pequeñas obras en las que se concentraba en muchos casos el talento del $\operatorname{artista}^{19}$.

Refiriéndose al relieve de marfil del Vaticano atribuido al Pippi y a las copias del tema de las que ya habló Morey recuerda la tradición de atenerse a un diseño de Miguel Angel que el identifica con el conservado en el Teylers Museo de Haarlem que debió inspirar al que hasta ahora se identificaba como obra de Daniele de Volterra, modelo de los relieves de marfil y que este autor considera obra del Piper ${ }^{20}$.

Se sitúa así este interesante relieve del Descendimiento en la orbita del miguelangelismo dramático que difería, en principio, del que aparece en algunas de las obras de Guglielmo, más próximas a las últimas creaciones de su admirado y gran maestro, como pudiera ser sus versiones de la Piedad de Palestrina con las que aparece más relacionado el Cristo riojano. No obstante no hay que olvidar que Piper, según opina su principal biógrafo, debió frecuentar el taller de Guglielmo en el que trabajaba su futuro socio Jacob Cobaert, Cope y conocer el diseño de Miguel Angel en Harlem que trasformó su estilo.

Para intentar definir con más precisión la huella del arte Guglielmo en obras de marfil localizadas en España se centró también la atención en la figura de Jacob Cornelisz Cobaert, conocido

\footnotetext{
${ }^{14}$ Sotheby's El Quejigal 22-26 mayo 1979.

${ }^{15}$ Economopoulos, 2013, 59, fig. 16.

${ }^{16}$ Fiamminghi a Roma. 1508-1608. 1995, 43-45.

${ }^{17}$ Roma di Sisto V. Le Arti e la Cultura. 1993, 376.

${ }^{18}$ Pérez de Tudela, 2007, p. 414. Es noticia que recuerdan distintas fuentes como menciona la autora.

${ }^{19}$ Economopoulos, 2013, I, 3 72- 94.

${ }^{20}$ Economopoulos, 2013, p. 80, fig. 27 y p. 85, fig. 28.
}

Arch. esp. arte, LXXXVIII, 351, JULIO-SEPTIEMBRE 2015, 243-262 ISSN: 0004-0428, eISSN: 1988-8511, doi: 10.3989/aearte.2015.15 
como Cope, que parecía presentar mejores perspectivas referentes a localizar alguna de sus documentadas obras de marfil que sirvieran de elemento de comparación en este análisis.

Se conoce bien su íntima relación con Guglielmo Della Porta como fundidor de sus conocidas series de la Pasión y de la Metamorfosis y que a la muerte del maestro se hizo incluso cargo de su taller durante una temporada ${ }^{21}$. Esta faceta es la más conocida de su actividad pero fuentes antiguas destacaron sus trabajos en el campo de la eboraria y mencionaron entre sus obras en marfil una Visitación l y Una fuente con Relieves con escenas de la Metamorfosis ${ }^{22}$. A estas noticias, dadas por Baglione y Bertolotti, se reducían las conocidas sobre su actividad en este campo y solo se discutía la atribución de la fuente decorada con relieves de la Metamorfosis, de la que existen varios ejemplares en diversos Museos europeos incluido uno que apareció en el comercio de arte madrileño, del que no se han tenido noticia posteriores ni se han localizado las fotografías que en su día se hicieron.

Sobre esta labor en marfil se han dado últimamente noticias de gran interés como la recogida por Economopoulos, quizás referida a la citada Visitación ${ }^{23}$ o la que sugiere Schmidt en su revisión completa de los documentos que proporcionó Bertolotti referentes a Giovanni Antonius Gualterius, del que se han localizado en España varios Crucifijos en marfil. Al parecer en la fecha de 1595 se menciona «un crocifisso que io aveva fatto de avorio da Iacomo Fiamengo a Montecavallo quele lavora in casa de uno Iacome romanesco...» y de nuevo respecto a otro asunto se le recuerda como Maestro Iacomo me disse frases que en el contexto del documento sugieren la actividad de este flamenco como maestro reconocido en su época en el arte del marfil en un ambiente de interrelacion profesional. La noticia sugirió que este Iacomo fiamengo pudiera ser el Jacob Cornelisz Cobaert, conocido como Cope, pero los datos que por ejemplo da Baglione sobre su misantropía que elude la compañía de cualquier persona aunque posteriormente Bertolotti asegura que se trata con regularidad con sus compatriotas flamencos, aconsejan esperar algún dato documental que apoyen esta hipótesis ${ }^{24}$.

\section{El grupo del Descendimiento del Palazzo Venezia de Roma}

Últimamente, creemos que con más fundamento, se le atribuye un interesante grupo en marfil del Descendimiento, en el Palacio Venezia de Roma cuyo crucifijo de proporciones muy estilizadas y su expresión dolorida aparece en cierta relación con el antes estudiado. La cita de Baglione sobre un Cristo muerto en brazos de su madre ha sugerido atribuir a este maestro este interesante Descendimiento de la cruz en marfil conservado en el Palazzo Venezia de Roma y que fue adquirido el año de 1987 de la familia Patricci o Patrizi, de origen sienés pero asentada en Roma desde 1537. Al parecer a partir de los inventarios del siglo XVIII se menciona entre los bienes de la familia un grupo de avorio e il Crocifisso que se identifica con esta pequeña obra que presenta en su dorso restos que indican contacto con madera que pudo pertenecer al Cristo de esta materia que se asocia con el grupo de marfil. Con recuerdos miguelangelescos como en las obras de su maestro Guglielmo y el indudable parecido de la cabeza de Nicodemo con la del San Mateo de mármol, obra documentada de Cope, la pequeña obra de marfil puede considerarse obra de este maestro ${ }^{25}$.

\footnotetext{
${ }^{21}$ Extermann 2012, 59-112. Sólo se citan los últimos estudios que conocemos y que recopilan su bibliografía más específica.

${ }^{22}$ Baglione, 1642, 100-101. Bertolotti, 1881, Recoge y discute sus noticias: Bever, 1948. Las amplía: Gramberg, 1960.

${ }^{23}$ Economopoulos, 2013, 52, nota 190.

${ }^{24}$ Bertolotti, 1884, 132. Recoge y transcribe entero el documento por primera vez: Schmidt, 2008, 5-20. La sugerencia de Schmidt; 2013, 37. Baglione; 1642, Bertolotti, 1880, 381, sobre sus contactos con sus compatriotas.

${ }^{25}$ Raggio, 1983, cat. 53: con errores rectificados por Barberini, 1989, 17-26.
}

Arch. esp. arte, LXXXVIII, 351, JULIO-SEPTIEMBRE 2015, 243-262

ISSN: 0004-0428, eISSN: 1988-8511, doi: 10.3989/aearte.2015.15 
Comparada esta pequeña obra con el Cristo riojano se encontraron ciertas afinidades estilísticas como es el abultamiento de las costillas que marcan casi un ángulo sobre el escurrido vientre, sus largos muslos y en conjunto su adelgazada silueta pero la disposición y factura de su cabellera apuntan con más claridad al Cristo de bronce de Guglielmo con el que antes se ha comparado.

\section{La difusión de los modelos de Guglielmo Della Porta en el taller romano de los Pozzo y en el del Buen Retiro (siglo XVIII)}

De todos es sabido que a partir del Renacimiento los grabados que difunde la imprenta y los famoso taccuini de los grandes maestros con los dibujos de sus creaciones, cada vez más comunes en el mundo artístico desde aquellos años, son la fuente directa de inspiración de la llamada pequeña escultura que a su vez se convierte en elemento trasmisor de estilos y formas en este trasiego de la cultura visual de todos los tiempos.

Un repaso de las obras de marfil que pudieron inspirarse en obras de Guglielmo Della Porta proporcionó interesantes datos sobre Giovanni Battista del Pozzo, del que se conoce una serie abundante de relieves inspirados literalmente en obras de Guglielmo Della Porta ya en fechas avanzadas del siglo XVIII. Recientes estudios las han sistematizado ${ }^{26}$ por lo que solo daremos una breve nota de la biografía de este artista.

Giovanni Battista del Pozzo nació en Bérgamo hacia 1670 y murió en Roma el año de 1752 donde trabajaba desde el año de 1697 posiblemente en el taller de los Hamerani, medallistas del Papa. Realizó para el Cardenal Albani bustos en marfil de filósofos de la Antigüedad y su primera obra conocida, firmada con su nombre y fechada en 1717, fue el medallón en marfil de Philipp Barón von Stosch conservado en el Museo de Berlin ${ }^{27}$. En un principio se confundió su personalidad con la de su hijo Andrea Pozzi, bien conocido en España por sus delicados trabajos para Carlos III en el taller de Buen Retiro, destinados éstos a la Casita del Príncipe de El Escorial. Llamado a Nápoles por el Monarca español se sabe por una carta de Van Vitelli que era hermano de Roque Pozzo el grabador romano documentado como hijo de Giovanni Battista ${ }^{28}$.

Unos primeros estudios sobre la obra de Giovan Battista se refieren a los famosos cabinets de Horace Walpole, hoy en el Museo Victoria y Alberto de Londres ${ }^{29}$ y el de Thomas Brand decorados con plaquetas de marfil de temas de la antigüedad ${ }^{30}$. Se conoce documentalmente, por las cartas de Walpole, que los relieves de su mueble debió adquirirlos en Roma en los años de su visita a la ciudad entre 1739-1741 y en su relación de 1774 se hace alusión a algunos como obra de Giovanni Battista del Pozzo. El mueble de Brand, amigo de Walpole, presentaba la misma estructura y decoración de plaquetas de marfil de estilo similar a las que decoran el mueble Walpole, las cuales

\footnotetext{
${ }^{26}$ Theurkauff, I, 1984, 114-118, cat-61 y 62. Idem,1986. Idem, II, 1994, 66-76. Cat. 24-28.

${ }^{27}$ Theurkauff, 1986, 241-246, nota 15, cat. 66.

${ }^{28}$ Estella, 1978, 57-64. No se mencionó entonces que Giovanni Battista era padre de Roque Pozzo el grabador entre otras obras de las Antigüedades de Herculano que sirvieron de modelo a los relieves de marfil de la Casita del Príncipe de El Escorial, en general obra de Andrea que por lo mismo era también hijo de Giovan Battista. Idem, 1999, 321-408 recogió la noticia y sugirió la probable colaboración de padre e hijo a la que nos referimos en este trabajo. González-Palacios, 1979-1980, 85-86 y cat. 541 a y b. Se refiere a la estancia en Nápoles de Andrea y a su próxima partida para España según informa por carta de 1763 el arquitecto Luigi Vanvitelli que era amigo de Roque, también en esas fechas en la ciudad partenopea.

${ }^{29}$ King y Longhurst, 1926 (reprint 1968) 128-129, figs. A-F. Trusted, 2013, 174-180. Recogió los antecedentes y añadió el estudio pormenorizado de sus plaquetas de marfil, atribuyendo a Giovanni Battista del Pozzo varios relieves entre los cuales el de Perseo Andrómeda.

${ }^{30}$ Edwards, 1931, 128-131, figs. A-B. El ejemplar de Brand se vendió en Christie's, 1980, cat. 24.
} 
también debió adquirirlas en Roma en sus estancias de 1738-1739 o de 1754-1755. No vuelven a aparecer noticias sobre este artista hasta tiempos recientes, con excepción de las obras que en el mercado de arte se han atribuido a su estilo.

Entre las obras de Guglielmo Della Porta, que fundió en bronce su discípulo Cope, destaca la serie de relieves con temas de la Metamorfosis de Ovidio. El artículo de Gramberg, el gran conocedor de la obra de este escultor, menciona el conjunto de plaquetas de esta serie que se conservan en el Museo de Hamburgo, que aumenta el número de las conocidas del Museo de Viena, de muchas de las cuales se han localizado copias tardías en marfil ${ }^{31}$.

\section{El relieve de la Danza de las Ninfas, Madrid}

En el primer volumen sobre la colección Winkler, Theurkauff se refiere a un relieve de marfil con la representación de Diana y Calixto al que clasifica como obra inspirada directamente -nachde una creación de Giovanni Battista Pozzo. El autor aclara que la obra presenta igual composición y estilo que otro relieve de marfil, cuya fotografía conserva el museo Victoria y Alberto de Londres del que se conoce su procedencia de la Abadía de Belweck, propiedad del Duque de Portland y que según aparece en las cuentas de su anterior propietario, el Earl de Oxford (1725-1726), era obra de Pozzo, sin especificar nombre, pero señalando que era la obra más fina que había realizado y que el Do (dito) era también el autor del Tormento de Marsyas relieve del que también se ocupa el autor en su segundo volumen de la colección citada ${ }^{32}$.

Ambos relieves que actualmente pueden analizarse a través de sus fotografías conservadas en el Museo Victoria y Alberto de Londres, son copias exactas de los del mismo tema que Jacob Cornelisz Cobaert, Cope, realiza en bronce siguiendo los modelos de Guglielmo Della Porta de su Serie de la Metamorfosis conservados en parte en el Museo de Bellas Artes de Viena y en otros Museos europeos. Esto indica que Giovanni Battista del Pozzo conocía bien la obra de Della Porta y sus fundiciones en bronce de Cope lo que justifica la clasificación de muchas placas de marfil con temas de esta serie cuyo estilo se ajusta a estas dos únicas documentadas del Pozzo, en algún caso como obras de su mano y en la mayoría de las conocidas como obras de su círculo.

Precisamente Christian Theurkauff ${ }^{33}$ aclaró esta distinción con el conjunto de las conservadas en la colección Winkler en un estudio comparativo profundo con las documentadas mencionadas que procedían de la Abadía de Belweek y en su línea Juttta Kappel ${ }^{34}$ añadió a este conjunto otra serie de relieves de los mismos temas de la Metamorfosis conservados en el Museo de Dresde y otros Museos alemanes a los que pueden añadirse algunos más del mercado de arte.

De hecho, hace ya muchos años, se conoció en Madrid un precioso relieve de formato rectangular que representaba La danza de las Ninfas $(13 \times 23 \mathrm{~cm})$ (fig. 5) clasificado como obra del Buen Retiro. Como se ha dicho y se recordará fue taller en el que se pudieron trabajar obras de este tipo por su hijo Andrea pues la semejanza de algunos de sus relieves, como la conocida plaqueta de Perseo y Andrómeda ${ }^{35}$, con el que del mismo tema del mueble Walpole se atribuye a su padre Giovanni Battista del Pozzo, entre otros detalles, apoyan la sugerencia de la colaboración de ambos en obras de este tipo ${ }^{36}$.

\footnotetext{
${ }^{31}$ Gramberg, 1960, 31-52.

${ }^{32}$ Theurkauff, 1984, Diana y Calixto, cat- 61; Idem, 1994 Tormento de Marsyas. Cat. 24.

${ }^{33}$ Theurkauff, I, 1986, nota 15 y cat. 66, 241-246 y II. 1994, cat. 24-289, 66-77 (estos últimos adquiridos en la subasta de Sotheby's julio, 1994).

${ }^{34}$ Kappel, 1997, 280-284.

${ }^{35}$ Estella, 1978, 63.

${ }^{36}$ Trusted, 2013, 175-178.
}

Arch. esp. arte, LXXXVIII, 351, JULIO-SEPTIEMBRE 2015, 243-262

ISSN: 0004-0428, eISSN: 1988-8511, doi: 10.3989/aearte.2015.15 


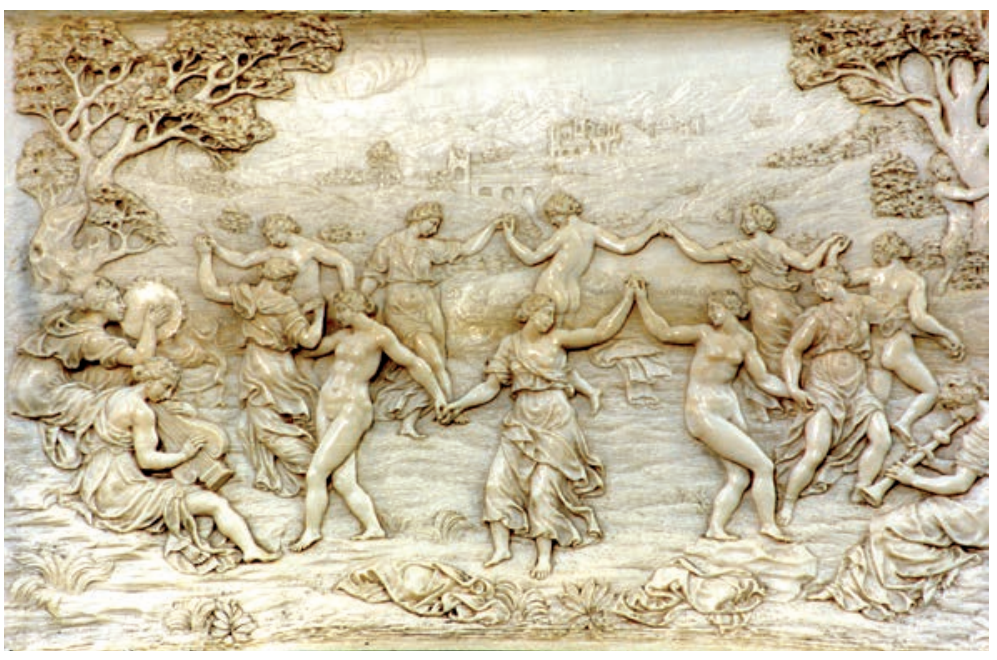

Fig. 5. Giovanni Battista Pozzo, círculo. La Danza de las Ninfas, marfil. Madrid. Mercado Arte (localización actual desconocida).

La Danza de las Ninfas se ajustaba literalmente al relieve en bronce del Museo de Hamburgo y a la terracota del Museo Victoria y Alberto de Londres que debió servir para la fundición del anterior, del mismo tema y ambas obras atribuidas a Cope por modelo de Guglielmo Della Porta ${ }^{37}$. Después de la fecha en la que se pudo estudiar la pieza en Madrid no se volvió a localizar en España hasta que hace unos pocos años se subastó en Sotheby's de Nueva York un relieve con el mismo tema con atribución a Giovanni Battista Della Porta. Philippe Malgouyres lo identificó con el que se describía en la guía de la Colección Rotschild por lo que es probable que el localizado en Madrid se conserve aún en una colección española y que a la vista de la floja ilustración del catálogo de Sotheby se le parecía mucho ${ }^{38}$.

En general las placas con relieves de la Metamorfosis por modelo de Guglielmo Della Porta se atribuyen al círculo de Giovanni pues por su difusión y la desaparición de por ejemplo las documentadas procedentes de la Abadía de Welbeck, es difícil definir su autoría por este artista. Por otra parte otros relieves que se conocen tanto de Giovanni como de su hijo Andrea, por ejemplo los de la Casita del Príncipe de El Escorial de este último o los muy similares que decoran el mueble de Walpole, algunos documentados como de Giovanni, y que sugieren como se ha dicho muy claramente el trabajo en común en estas obras de padre e hijo, orientan su estilo hacia un clasicismo que aunque quizás impuesto por sus modelos se diferencia del que define las plaquetas que representan las escenas de la Metamorfosis.

\section{Grupo de la Flagelación, Comercio de Arte, Madrid}

En tiempos recientes también se conoció un pequeño grupo de la Flagelación (fig. 6), de figuras exentas que se ajustaba muy exactamente a una composición de Guglielmo Della Porta ${ }^{39}$. Repre-

\footnotetext{
${ }^{37}$ Gramberg, 1960, figs. 10-12.

${ }^{38}$ Sotheby's 2000, La ficha no aclara su procedencia ni el parecido con la obra de Coppe pero su clasificación como del círculo de Giovanni Battista del Pozzo sugiere que se basó en los trabajos de Theuerkauff. Agradezco a la Sra. Londono de esa institución, su amabilidad por proporcionarme las páginas del Catálogo en las que se reproduce. La fotografía que se adjunta es la que tuvimos del ejemplar madrileño en su día, cortada en parte a su lado derecho. Malgouris, 2010, 120, cat. Le Banquet des Dieux y Le Massacre des Niobides.

${ }^{39}$ Coll-Cortes, 2012, Madrid.
} 


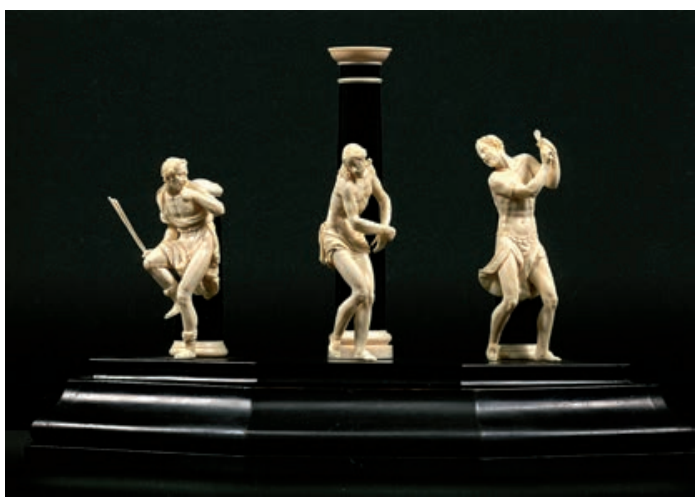

Fig. 6. La Flagelación, marfil. Madrid. Mercado de arte.

Fig. 7. Guglielmo Della Porta. La Flagelación, bronce. Londres, colección particular (procede de mercado de arte).

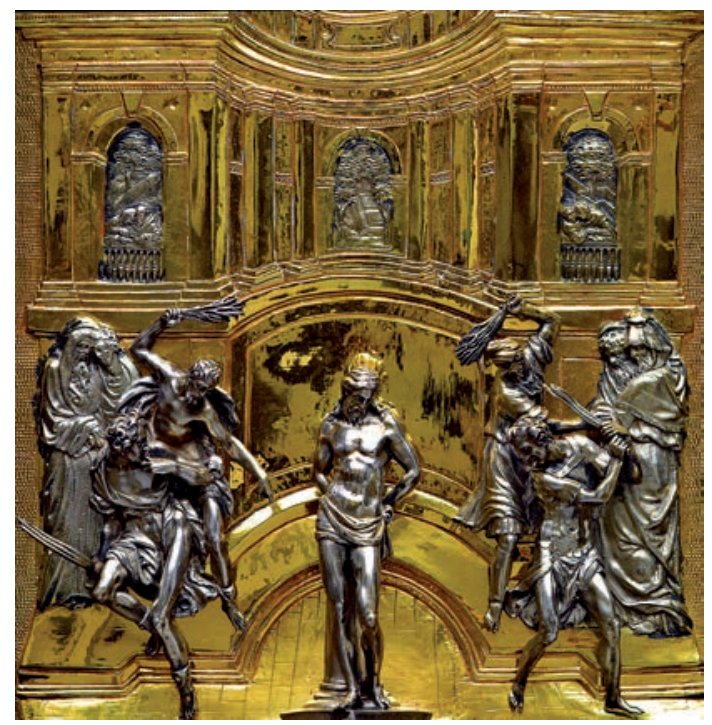

senta a Cristo $(19 \mathrm{~cm})$ con cabellera de lisos rizos inclinado hacia la derecha y la cabeza en actitud contrapuesta, sobre el pecho. Los brazos hacia delante muestran sus muñecas atadas y su cuerpo, de anatomía bien concebida, cubierto a partir de la cintura por paño de pureza de pliegues lisos. El movimiento de las piernas arquea la figura con la derecha avanzada hacia el frente y retrasada la izquierda, de muslo muy largo. Al dorso, la espalda señala de fina manera las vértebras de la columna. La figura destaca el blanco brillante del marfil ante una sencilla columna de madera negra con simple capitel dórico de marfil.

A la izquierda uno de los sayones, en movida actitud como dispuesto a propinar el golpe con una larga vara, apoya su cuerpo sobre la pierna derecha que también presenta un largo muslo, en tanto que a izquierda, doblada hacia atrás, marca el impulso de la figura cubierta por una túnica de pliegues muy específicos como el que se conforma en forma de U sobre el muslo derecho, o los que recogidos al frente, dejan al aire el pecho musculoso de su anatomía. De cabeza muy bella de perfil, con cabellera de rizos acaracolados, lleva su mano a la boca en gesto de esfuerzo ¿o de burla? El sayón a la derecha sujeta con ambas manos el flagelo en actitud contrapuesta al sayón de la izquierda, más contorsionado. Su cabeza hacia la izquierda mirando al Cristo en tanto que su cuerpo, hacia la derecha, se cubre con fina ¿camisa? que transparenta el esfuerzo muscular del cuerpo y remata en lengüetas como las que adornan las corazas a la romana.

El grupo asienta en base ovalada conformada en tres bajas secciones que a la altura de los sayones se marcan con filetes de marfil.

Su iconografía se basa en los textos evangélicos, como el de Mateo $(27,26)^{40}$ : Entonces les soltó a Barrabás y a Jesús, después de haberlo hecho azota, le entregó para que fuese crucificado.

También en el Mercado del arte ha aparecido un precioso relieve de la misma composición representada sobre una placa de bronce dorado y figuras en relieve de plata ${ }^{41}$ (fig. 7). La atribución a Guglielmo tiene el claro fundamente de no solo la documentación que menciona obras similares del artista sino también su semejanza con un serie de dibujos del conocido Skizzenbuch del artista.

\footnotetext{
${ }^{40}$ Sagrada Biblia, ed. 1960.

${ }^{41}$ Coppel, 2012, 74-90.
}

Arch. esp. arte, LXXXVIII, 351, JULIO-SEPTIEMBRE 2015, 243-262

ISSN: 0004-0428, eISSN: 1988-8511, doi: 10.3989/aearte.2015.15 
Entre las versiones del tema realizadas por Guglielmo destaca, con referencia al grupo de marfil, la conservada en el Museo Bargello de Florencia. Sus figuras de plata del Cristo y los sayones y detalles de la indumentaria aparecen en el grupo de marfil ${ }^{42}$.

El parecido de la composición con la obra de Guglielmo Della Porta sugería que fuese obra de su taller inspirada en este caso en otra de sus conocidas series fundidas por el citado Jacob Cornelisz Cobaert o Cope, la llamada de Historias De la Pasión, menos divulgada que su Serie de la Metamorfosis de Ovidio.

Revisadas las versiones de la Flagelación, la escena menos divulgada del Ciclo de la Pasión, difería estilísticamente del grupo que se estudia aunque su composición, como se ha dicho, se ajustara literalmente a la representada en relieve en la obra de Guglielmo ${ }^{43}$. Tampoco se vieron afinidades de las finas esculturillas que lo conforman con el citado grupo del Descendimiento atribuido a Cope ni con la obra conocida del Pippi, el otro escultor flamenco que trabaja en Roma del que se ha mencionado su ocupación en la talla del marfil y cuya importante obra escultórica se desarrolla por estos mismos años de la actividad del Frate del Piombo, como se denominaba frecuentemente al Della Porta.

Ello aconsejó buscar otro camino en la investigación, basada en la difusión de los modelos del gran maestro que a través de sus discípulos y de sus dibujos se mantuvo durante largos años y como se ha visto hasta bien avanzado el siglo XVIII. De hecho, al comparar las figurillas de este grupo de la Flagelación con el relieve citado de Guglielmo que le sirve de modelo, se advirtieron otros detalles; así, por ejemplo, el específico pliegue en forma de U cerrada en el sayón de la derecha del bronce, simplifica sus dobleces en la figura correspondiente del marfil y en conjunto los adustos rasgos fisionómicos de los personajes del relieve en bronce se suavizan en los del marfil, graciosos en cierto modo con un sentir dieciochesco.

Con estos antecedentes se indagó sobre la posibilidad de que el grupo de la Flagelación pudiera ser también obra salida del taller de los Pozzo pero para facilitar la comparación se intentó localizar alguna de sus obras exentas de marfil además de las vistas en relieve.

Se pensó en las figurillas que rematan el mueble de Walpole pero se sabe que son de Jacobo Frans Vescovers o Verskovis, otro artista flamenco que trabaja en Roma ${ }^{44}$ pero cuyo estilo difiere del que muestran las obras del taller de los Pozzo. También se conocen los relieves del Hércules y la Flora Farnesio, pequeñas figurillas de marfil firmadas por Andrea Pozzi (ca.1780) ${ }^{45}$ curiosamente repetidos ambos relieves tanto en el mueble Walpole como en el de Brand y en la Casita del Príncipe de El Escorial hay figuras exentas de marfil como las de la Puditia o el Desengaño, siempre ajustadas literalmente a sus respectivos modelos italianos pero que son obra del taller del Buen Retiro dirigido por Andrea Pozzi ${ }^{46}$.

La comparación de estas obras con las que aparecen en el grupo de la Flagelación no aporta claridad al estudio y se ha visto que los personajes de este pequeño conjunto aparecen más relacionados con personajes de algunas de las plaquetas de marfil del taller español. Así el rostro del sayón a la izquierda presenta rasgos fisionómicos muy similares a los que aparecen en el Centauro Furietti (fig. 8) que se repiten en el Teseo de la plaqueta de Teseo dando muerte al Minotauro en línea clara de las firmadas por Andrea Pozzi, todas ellas en El Escorial. Como se ha dicho debió colaborar en las obras de su padre, como denuncian los casos citado de por ejemplo la plaqueta de Perseo y Andrómeda en el mueble Walpole ${ }^{47}$ absolutamente idéntico al que con el mismo tema

\footnotetext{
${ }^{42}$ Coppel, 2012, 87, fig. 43.

${ }^{43}$ Extermann, 2012.

${ }^{44}$ King y Longhurst, 1926. Edwards, 1939. Trusted, 2011, 175-176: sobre el mueble Walpole, recoge la anterior bibliografía y como se ha dicho atribuye a Giovanni Battista del Pozzo varios de sus relieves de marfil.

${ }^{45}$ Sotheby's, 1986, 371.

${ }^{46}$ Estella, 1978.

${ }^{47}$ Trusted, 2013, 178 (148, 14).
}

Arch. esp. arte, LXXXVIII, 351, JULIO-SEPTIEMBRE 2015, 243-262 ISSN: 0004-0428, eISSN: 1988-8511, doi: 10.3989/aearte.2015.15 
se conserva en El Escorial y los relieves del Hércules y la Flora Farnesio, firmados por Andrea Pozzo, como se ha dicho similares a los reproducidos en este mismo mueble ${ }^{48}$.

O el muy curioso de Leda y el Cisne del mueble Brand que repite literalmente la atrevida composición del relieve que aparece en una chimenea de la Alhambra, obra documentada de Giacomo Della Porta, el padre de Guglielmo ${ }^{49}$. La sugerente asociación de Giovanni Battista con su hijo Andrea justifica estos y otros detalles comunes advertidos en obras de $\operatorname{ambos}^{50}$. También el plegado, los lisos torsos de pectorales marcados y sobre todo la fina factura y delicadeza de la talla del marfil apuntan a su realización en un taller de la calidad de los dirigidos por los Pozzo fuese en Roma, más probablemente, o en Madrid.

Desde otro punto de vista, las movidas actitudes de los personajes de la Flagelación aunque exigidas por el tema representado recuerdan las que presentan los personajes de la Serie de David de El Escorial ${ }^{51}$ (fig. 9), relieves inspirados en alguna de las series de grabados de por ejemplo Preciado de la Vega que difundieron los frescos de las Logias rafaelescas de Perino de la Vega, pintor cuya relación con Guglielmo Della Porta es bien conocida. La escena de David y Goliat por grabado de Orazio Borgiani ${ }^{52}$, presenta detalles estilísticos que recuerdan los que aparecen en los relieves de marfil atribuidos al círculo de Giovanni

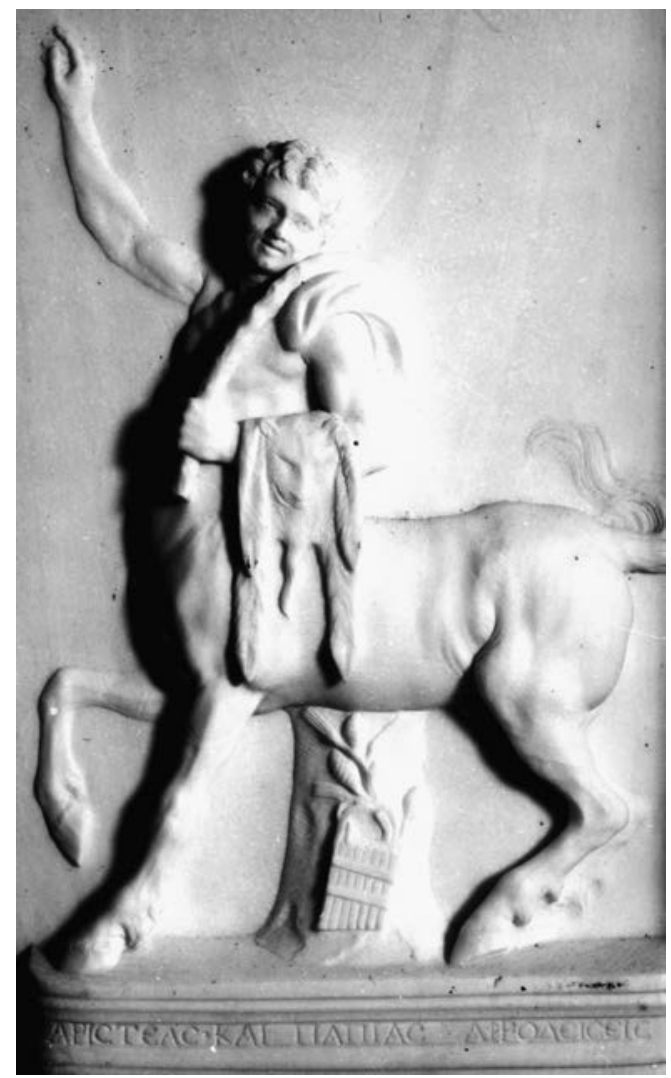

Fig. 8. Andrea Pozzo, El Centauro Furietti, marfil. El Escorial (Madrid), Casita del Príncipe. Battista del Pozzo de la colección Winkler como puede comprobarse en la figura caída de Goliat que recuerda en la posición de sus brazos a la que también en primer término aparece en la escena de la Metamorfosis que representa la Muerte de los hijos de Niobe ${ }^{53}$ inspirada en uno de los bronces del mismo tema de Guglielmo Della Porta fundido por Cope, conservado en el Museo de Viena.

Ninguna de las plaquetas de esta serie de David presentan la firma de Andrea Pozzi por lo que su clasificación en su día no la relacionamos con su obra pero conocida ahora la de Giovanni Battista, principalmente la representada en las escenas de la Metamorfosis, puede sugerirse que este conjunto con las escenas del personaje bíblico obra del taller del Buen Retiro esté en relación con la dirección o inspiración estilística de este último en su supuesta colaboración de padre e hijo. No es óbice a lo expuesto a la intervención de otros artistas algunos españoles en la labor del taller

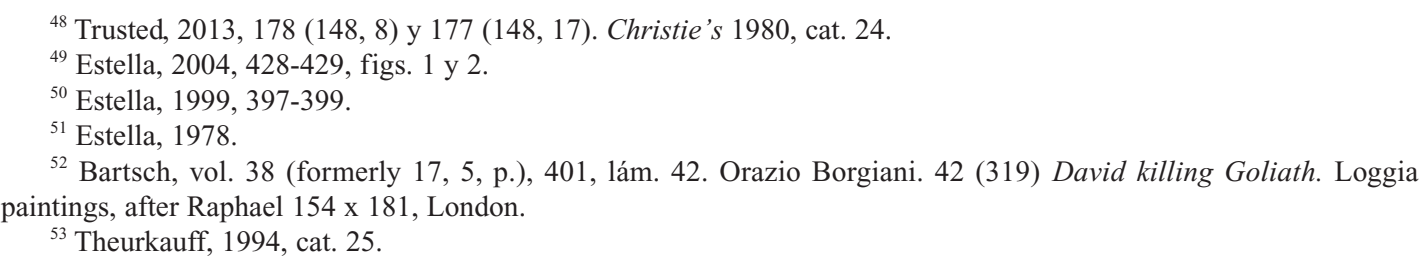

Arch. esp. arte, LXXXVIII, 351, JULIO-SEPTIEMBRE 2015, 243-262

ISSN: 0004-0428, eISSN: 1988-8511, doi: 10.3989/aearte.2015.15 


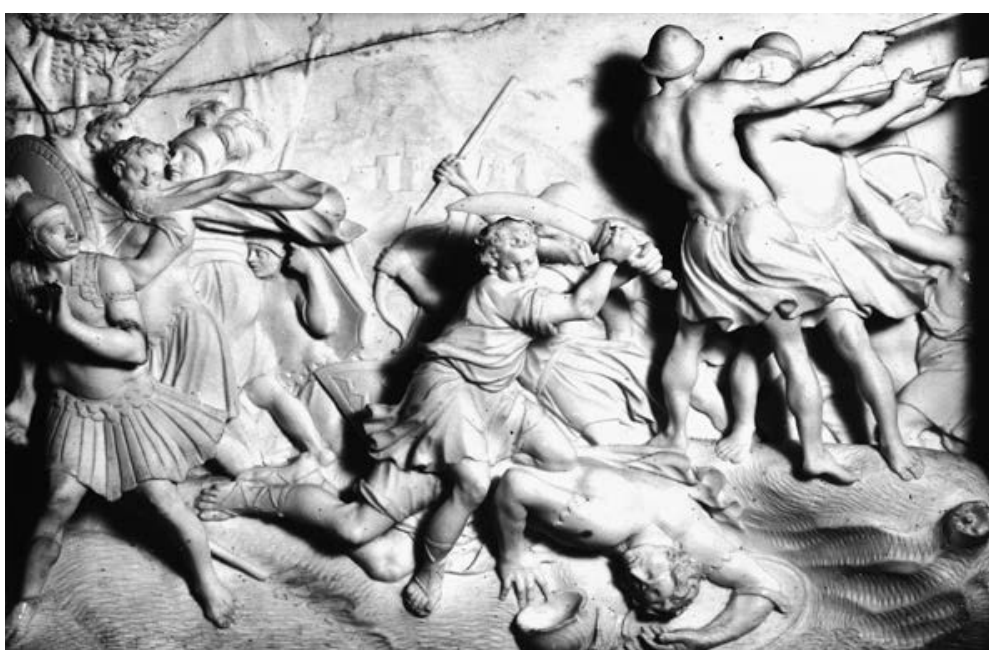

Fig. 9. ¿Taller de los Pozzo? David y Goliat, marfil. El Escorial (Madrid), Casita del Príncipe.

del Buen Retiro o Real Fábrica de Marfiles como concretamente se sabe del pago a Nicolás de Arce de dos bajorrelieves de las Historia de Herculano ${ }^{54}$, fuente impresa inspiradora de la mayor parte de los relieves de la Casita del Príncipe de El Escorial, pues la dirección de Andrea Pozzo se imponía a todos sus colaboradores.

El cambio de estilo de las composiciones puede ser debido a sus distintas fuentes de inspiración lejos de los temas de la Antigüedad que priman en la obra de Andrea ajustadas muchas de ellas a los grabados de su hermano Roque Pozzo de las Antigüedades de Herculano pero que según se ha dicho también aparecen en la obra de Giovanni en los citados muebles de Walpole y Brand. También es posible que los ejemplos destacados fuesen, como se ha sugerido, obra de Andrea trabajando ya en aquellos años anteriores a su venida a España llamado por Carlos III, desde al menos el 1764 cuyo nombre se menciona en las nóminas reales, en colaboración con su padre en su taller romano hasta que éste muere hacia 1752. Esta fecha también apoya la muy probable colaboración de su hijo en sus obras dada la adquisición en Roma de los relieves de los muebles de Walpole, hacia 1740 y de la posterior de los que decoran el mueble Brand, algunos de los cuales pudieron ser adquiridos en su segundo viaje a Roma de 1754 cuando ya había muerto Giovanni Battista.

Otro aspecto que no se trató en su día fue el gran número y distinto formato de los numerosos relieves existentes en la Casita del Príncipe del Escorial, de muchos de los de cuales no se dio nota en su día. Muchos de ellos siguen los mismos modelos de Herculano pero otros se ajustan al estilo más movido de las escenas de la Metamorfosis.

Posiblemente este gran número de relieves y sus distintos formatos debieron de encargarse para decorar algún mueble o más bien varios, como aparecen en los mencionados de Walpole y Brand. En su conjunto se ajustan al sosegado estilo de Andrea aunque impuesto por sus modelos, también en su mayoría los grabados de las Antigüedades de Herculano, en parte obra de su hermano Roque, pero otros, los menos, recuerdan las movidas escenas de los relieves de la Metamorfosis de Giovanni, el patriarca de la familia.

Todo lo dicho no es suficiente para poder atribuir esta Flagelación a los Pozzo pero si para sugerir que es obra de su círculo, de un artista posiblemente trabajando en Roma a mediados del

\footnotetext{
${ }^{54}$ Junquera, 1979, 77.
}

Arch. esp. arte, LXXXVIII, 351, JULIO-SEPTIEMBRE 2015, 243-262 ISSN: 0004-0428, eISSN: 1988-8511, doi: 10.3989/aearte.2015.15 
siglo XVIII, con fácil acceso a la obra de Guglielmo y a las fundiciones por Cope de las historias de su Serie de la Metamorfosis.

\section{Los talleres franceses de Dieppe y el de Saint Claude (Franco Condado)}

En el desarrollo del arte del marfil en el siglo XVIII destaca la rica producción que por aquellas fechas se llevaba a cabo en los talleres franceses de Dieppe. Minusvalorada por la crítica se ha olvidado con demasiada frecuencia que en ellos se habían formado escultores del arte del marfil tan finos como David Le Marchand o Jean Baptiste Belleteste ${ }^{55}$.

También destaca en los mismos años las obras del taller de Saint Claude en el Franco Condado con escultores consagrados que trabajan el marfil como Jaillot o Vuillerme y en un plano en cierto modo más artesanal los miembros de la familia de los Rosset ${ }^{56}$.

Ambos talleres, aparte de la producción de sus artistas más preclaros como los citados, trabajan el marfil con técnicas en cierto modo artesanales y como se ha dicho divulgan por toda Europa sus creaciones, muy generalmente religiosas, ya desde los años medios del siglo XVII. En ocasiones se confundieron con algunas de los talleres del Buen Retiro por lo que su estudio interesaba para diferenciar sus caracteres en piezas de dudosa atribución, como la de los finos y conocidos relieves de la Coronación de Espinas y de la Flagelación, del Museo del Prado, atribuido por Pérez Villamil a Andrea Pozzo ${ }^{57}$, y otros.

\section{Los dos relieves de colección alicantina}

Precisamente en colección particular española se han localizado dos bellos relieves que representan dos de las estaciones de los tradicionales Via Crucis, devoción católica que conmemora las escenas de la Pasión. El dedicado al episodio de El Cirineo ayuda a llevar la cruz a Jesús (fig. 10), presenta en su ángulo inferior a la derecha una pequeña marca con la silueta somera de un hacha que no se repite en el segundo de Jesús consuela a las mujeres de Jerusalén (fig. 11).

En una primera revisión de posibles obras similares, se localizaron ocho relieves de un Via Crucis junto a un Cristo, todo el conjunto de marfil, que en su día estuvo adosado a un pilar en la iglesia de Notre Dame en la ciudad francesa de Boulogne sur $\mathrm{Mer}^{58}$. La noticia incluía la ilustración de la escena de la Condena a muerte de Jesús o Lavatorio de las manos de Pilatos (fig. 12), cuyo formato, medidas y estilo coincidían totalmente con los que aparecen en los relieves españoles y que además presentaba en la esquina inferior derecha el detalle de la silueta del hacha. Por todo ello se consideró que los relieves españoles pertenecían al Vía Crucis francés del que se localizaron otros dos relieves con lo que solo parece que faltan los dos relieves de las dos Estaciones no representadas, concretamente Jesús encuentra a su Madre y Jesús muere en la Cruz.

La dispersión de las plaquetas parece deberse al hecho a que la Catedral de Boulogne sur Mer, donde se exhibía en principio el Vía Crucis, fue destruida por un incendio en 1798.

\footnotetext{
${ }^{55}$ Milet, 1904: se menciona únicamente este texto como una de las primeras fuentes escritas sobre este taller.

${ }^{56}$ Brune, 1912. Les Rosset, 2002 (recoge el estudio introductorio de Marie-Liesse Pierre, sobre los Rosset y el desarrollo de su taller).

${ }^{57}$ Blanco y Lorente, 1969, nº s. 278 y 283 (habrá que revisar la atribución en trabajos posteriores).

${ }^{58}$ Las entradas fundamentales de Google bajo el epígrafe: Notre Dame de Boulogne sur Mer, Vía Crucis a las que se añadieron otras. En general las noticias proceden de la Medioteca Francesa de la Arquitectura y Patrimonio Nacionales del Ministerio de Cultura.
}

Arch. esp. arte, LXXXVIII, 351, JULIO-SEPTIEMBRE 2015, 243-262

ISSN: 0004-0428, eISSN: 1988-8511, doi: 10.3989/aearte.2015.15 

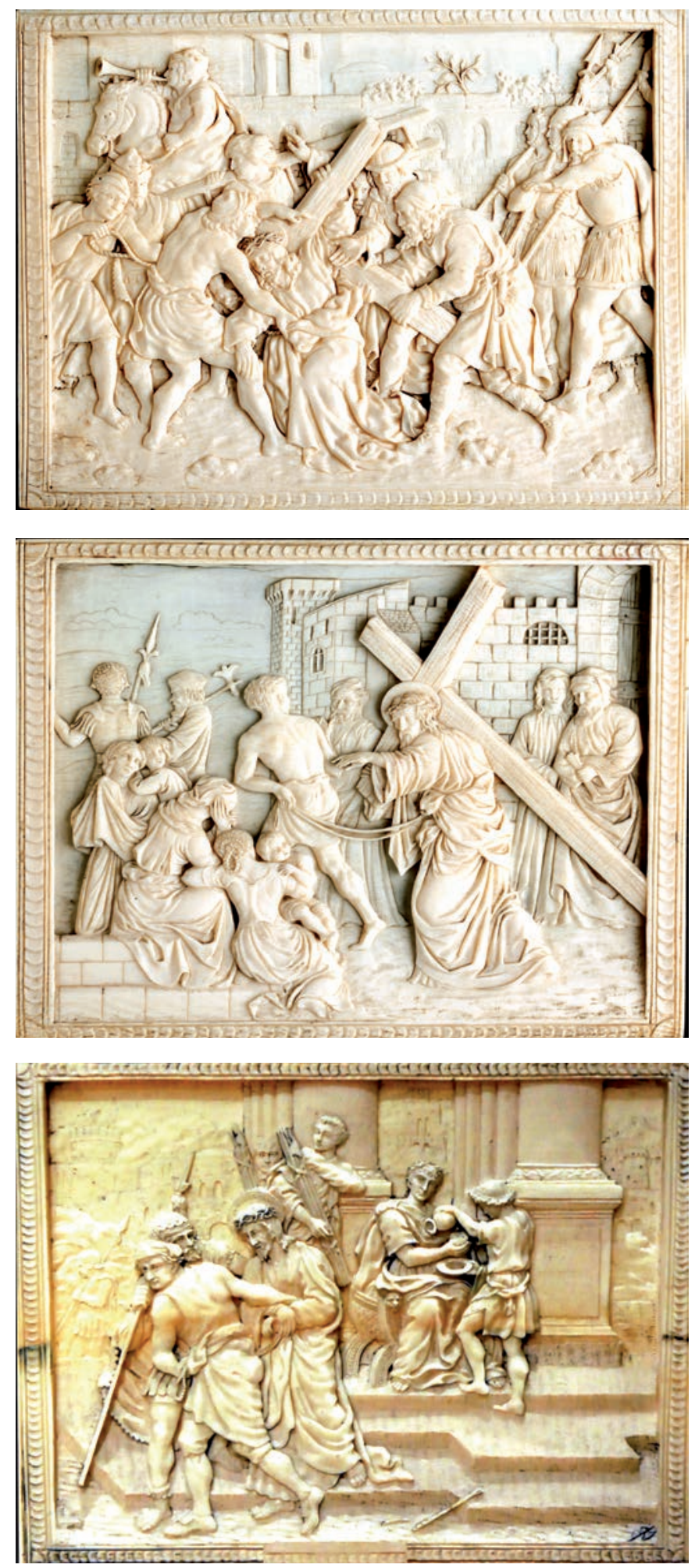

Fig. 10. ¿Taller de Saint Claude? El Cirineo ayuda a llevar la cruz a Jesús, marfil. Novelda (Alicante), colección particular.

Fig. 11. ¿Taller de Saint Claude? Jesús consuela a las mujeres de Jerusalén, marfil. Novelda (Alicante), colección particular.

Fig. 12. ¿Taller de Saint Claude? Condena a muerte de Jesús (Lavatorio de las manos de Pilatos), marfil. Boulogne sur Mer. Catedral. Plaqueta del Via Crucis.

Arch. esp. arte, LXXXVIII, 351, JULIO-SEPTIEMBRE 2015, 243-262 ISSN: 0004-0428, eISSN: 1988-8511, doi: 10.3989/aearte.2015.15 
Por la localización geográfica del Via Crucis, su tema y la calidad de sus relieves se pensó que podía ser obra del taller de Saint Claude como el de su posible procedencia y por las mismas razones se revisó la obra de los Rosset, los más conocidos como posibles autores de obras de este tipo pues entre los datos recogidos de Google destaca el que menciona literalmente Crucifix en ivoire. Ministère de la Culture... croix ou crucifix attribué aux Rosset sin mencionar la fuente de donde procede la noticia y que por otra parte no aclara bien si los Rosset son los autores del Crucifijo o de la cruz que conforman los relieves de la Pasión.

Revisada la bibliografía conocida sobre estos artistas y más concretamente el Catálogo de la Exposición que se hizo en Dole de parte de su obra ${ }^{59}$ se comprobó que en ninguno de los textos consultados se refieren al detalle del hacha por lo que se indagó en otro campo, el de la porcelana de Sèvres donde otro Rosset, de nombre Pierre Rosset L'Ainé, que no coincide con ninguno de los nombres propios de los Rosset de Saint Claude, en general escultores trabajando en marfil, tenía como marca distintiva un hacha, de silueta similar a la que presenta este detalle en los relieves de marfil del Vía Crucis de Boulogne sur Mer $^{60}$.

De este Rosset no se han conseguido más datos del que le presenta como diseñador de las finas piezas de porcelana destacando su preferencia por bellos motivos florales y paisajísticos. Por ello se intentó relacionar el taller de Saint Claude con la factoría de Sèvres lo cual en principio no era fácil por ser campos muy diferentes tanto en sus técnicas como en los materiales empleados. Solo se ha localizado una noticia sobre esta posible relación en un dato conocido sobre el más famoso de los Rosset, Jean-François-Joseph Rosset, dit Dupont, conocido vulgarmente como Joseph Rosset y famoso por sus bustos en marfil de Voltaire y de otros personajes célebres de su época. Se sabe que Rosset envió a la fábrica de porcelana de Sèvres un busto de marfil de Voltaire, el más destacado por la crítica de entonces, para que se reprodujera en este medio preferido por algunos de los amateurs de la época ${ }^{61}$.

Aunque con esta noticia puede sugerirse que los contactos entre Saint Claude y Sèvres existieron y que el apellido Rosset puede sugerir un posible parentesco de los artistas citados, el estudio estilístico de las obras conocidas de los Rosset no apoya su hipotética autoría del Via Crucis y de las plaquetas en estudio, por lo que de momento parece que lo mejor es adscribirlos como en un principio se propuso como obras de un taller francés, posiblemente de algún artista formado en el de Saint Claude, en general de un arte más fino que el de los formados en Dieppe.

$\mathrm{Su}$ cronología viene condicionada a la fecha de la destrucción de la iglesia y en cierto modo al detalle del hacha que según la Sra. Aréchaga, experta en el estudio de la porcelana europea de estas fechas, sólo se utiliza por Pierre Rosset a partir de los años de la revolución francesa, es decir

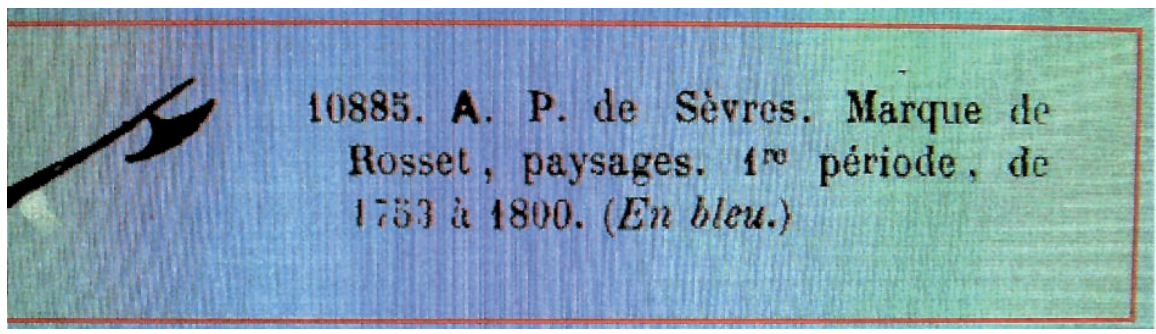

\footnotetext{
${ }^{59}$ Les Rosset. Agradezco al Sr. Monier que me facilitara su envío por el Museo.

${ }^{60}$ Agradezco a Carmen Aréchaga, especialista en este campo de la porcelana, las noticias sobre este artista que confirman las dadas en Google sin referencias a fuentes. El motivo del hacha al parecer se reproduce más o menos por los años de la revolución francesa.

${ }^{61}$ Les Rosset, 20-21.
}

Arch. esp. arte, LXXXVIII, 351, JULIO-SEPTIEMBRE 2015, 243-262

ISSN: 0004-0428, eISSN: 1988-8511, doi: 10.3989/aearte.2015.15 
los últimos años del siglo XVIII. Dado que el estilo difiere de los de los Rosset, habrá que buscar el antecedente de este detalle en fechas anteriores.

Desde otro punto de vista se recordó que tanto las obras pictóricas como las de la escultura monumental y más frecuentemente los objetos de la llamada pequeña escultura se inspiran en muchos casos en grabados, a su vez reproducciones en esta técnica de obras pictóricas o escultóricas de los grandes maestros.

Buscando modelos grabados que hubieran podido inspirar a los artistas de este Vía Crucis de momento sólo se pudo constatar que otras series de este tema iconográfico en el campo de la escultura o en otros campos artísticos seguían modelos de caracteres neoclásicos con escenas claramente delineadas destacando de ricos fondos de arquitecturas monumentales, a veces inspiradas en modelos renacentistas en cierto modo a como se ha visto en la obra de los Pozzo y como puede advertirse en los relieves del Museo del Prado, que no obstante no nos parece encajen con la obra de los Pozzo pero tampoco pueden asimilarse a los de Saint Claude vistos, pues son mucho más finos. Hay que recordar que en el taller de los marfiles del Buen Retiro trabajaron otros artistas españoles $^{62}$ de los que apenas se conocen sus obras como Dionisio Sancho, del que modernamente se ha documentado el bello Resucitado de marfil, de la Casita del Labrador de Aranjuez ${ }^{63}$ y sin olvidar otras obras de Arce, además de la mencionada, de por los mismos años ${ }^{64}$.

No se ha conseguido localizar el modelo concreto que posiblemente proceda de alguno de los grabadores franceses de esa época que difundieron no sólo las grandes composiciones pictóricas sino las más tradicionales que predominan en el campo de lo religioso. De hecho se ha localizado un interesante Vía Crucis de esmaltes de Limoges en la iglesia de Notre Dame en Avranches (Normandía, Francia) cuyas escenas repiten las composiciones del Vía Crucis de Boulogne aunque no literalmente pero de forma muy aproximada, como puede advertirse en la representación de la primera estación del Lavatorio de las manos de Pilatos o Jesús condenado a muerte. Se insistió en localizar series conocidas de este tema, como la conocida de los grabados de Gamborino de la serie del Vía Crucis por dibujos de Vicente López $^{65}$ que por las fechas podía proporcionar alguna luz al problema, pero no recordaban a las escenas representadas en los marfiles de Boulogne.

A la espera de posibles publicaciones en el curso de la restauración del Vía Crucis de Boulogne sur Mer, que quizás proporcionen noticias documentales se mantienen las sugerencias expuestas sobre sus posibles autores y cronología.

\section{BIBLIOGRAFÍA}

Avery, Charles (2012): “Guglielmo Della Porta's relationship with Michelangelo”. En: Coll-Cortés, Guglielmo Della Porta. A Counter-Reformation sculptor, pp. 114-137.

Baglione, Gio (1935): Le Vite dei Pittori . . . Del Pontificato de Gregorio XIII del 1572. In fino a tempi di Papa Urbano nel 1642. Roma.

Barberini, Maria Giulia (1989): “Cope scultore fiammingo ed un avorio di Casa Patrizi”. En: Per Carla Guglielmi. Scritti di allievi. Roma, 17-25.

Bartsch (1983): The Illustrated Bartsch, 38 (formerly 17, part 5). En: "Italian artists of the sixteenth century" (Edited by Sebastian Buffa). Nueva York: Abaris Book.

\footnotetext{
${ }^{62}$ Junquera, 1979.

${ }^{63}$ Jordán De Urriés, 2009, 174 y nota 69.

${ }^{64}$ Estella, 1984. I, figs. 71 y 74-77; II. 43-45: recoge la bibliografía anterior sobre el artista.

${ }^{65}$ Díez, 1999, I Cap. XII, p. 404 y Cat. E-45 a E-55.
}

Arch. esp. arte, LXXXVIII, 351, JULIO-SEPTIEMBRE 2015, 243-262 ISSN: 0004-0428, eISSN: 1988-8511, doi: 10.3989/aearte.2015.15 
Bertolotti, Antonino (1884): Artisti subalpini in Roma nei secoli XV, XVI e XVII. Ricerche e Studi negli Archivi romani, Mantua.

Bertolotti, A. (1974 reimp.): Artisti belgi e olandesi a Roma nel secoli XVI-XVII. Roma 1885 (ed. en 1880).

Bertolotti, A. (1975): Artisti francesi in Roma nei secoli XV, XVI e XVII. Ricerche e Studi negli Archivi Romani. Ristampo dell edizione de Mantova 1886. Bolonia, Forni.

Bever, Geneviève (1946): Les “Tailleurs d'Yvoire” de la Renaissance au XIX siècle. Bruselas.

Blanco, Antonio / Lorente, Manuel (1969): Catálogo de la Escultura. Museo del Prado. Madrid.

Brune, L'abbé Paul (1912): Dictionnaire des artistas et ouvriers d'art de la Franche Comté. París.

Christie's Fine English Furniture no 24, Londres, 27 de noviembre de 1980.

Coll-Cortés (2012): Guglielmo Della Porta, a Counter-Reformation sculptor. Madrid.

Coppel, Rosario (2012): “Guglielmo Della Porta in Rom”. En: Coll-Cortés, Guglielmo Della Porta, a Counter-Reformation sculptor, Madrid, 28-113.

Díez, José Luis (1999): Vicente López (1772-1850) (Vol. I, Vida y obra). Madrid: Fundación de Apoyo a la Historia del Arte Hispánico.

Economopoulos, Harula (2013): Stefano Madernno, scultore. 1571ca. 1636; i maestri, la formazione, le opere giovanili. Roma: Gangemi.

Edwards, Ralph (1931): "Cabinets made for Horace Walpole and Thomas Brand". En: Burlington Magazine, march, 128-131, figs. A y B.

Estella Marcos, Margarita Mercedes (1978): “Casita de EL Príncipe de El Escorial”. En: Reales Sitios, 3er trimestre, 57-64.

Estella Marcos, Margarita Mercedes (1984): La escultura Barroca de marfil en España. Las escuelas europeas y las coloniales, 2 vols. Madrid: CSIC.

Estella Marcos, Margarita Mercedes (1999): "La escultura de marfil en España”. En: Artes Decorativas, I. Summa Artis XV. Madrid, pp. 321-408.

Estella Marcos, Margarita Mercedes (2004): “La importación de escultura italiana. Obras en España del taller de los Della Porta, Giambologna y del Naccherino". En: El modelo italiano en las Artes Plásticas de la Península Ibérica durante el Renacimiento. Valladolid: Universidad de Valladolid, pp. 423-454.

Estella Marcos, Margarita Mercedes (2012): "Guglielmo Della Porta: early years and some of his work in Spain”. En Coll-Cortés: Guglielmo Della Porta e Counter. Reformation sculptor, Madrid, pp. 114-26.

Extermann, Grégoire (2012): "Il ciclo della Passiones di Cristo di Guglielmo della Porta". En: Scultura a Roma nella seconda metá del Cinquecento. Protagonisti e Problemi. (A Cura di Walter Cupperi, Grégoire Extermann, Giovanna Ioele). Roma: Universitá Roma, 3, pp. 59-112.

Dacos, Nicole / Meijer, Bert W. (commissaires) (1995): Fiamminghi a Roma. 1508-1608. Artisti des Pays Bas et de la Principauté de Liège à Rome à la Renaissance, Bruselas.

González-Palacios, Alvar (1979-1980): "Le arti decorativi e l'arredamento alla Corte di Napoli, 1734-1805". En Civiltá del '700 a Napoli, 1734-1799. 2 vol., Nápoles, diciembre-noviembre. 75-956, cat (avori) 541 a y b.

Gramberg, Werner (1960): “Guglielmo Della Porta. Coppe Fiammingo und Antonello da Faenza- Bemerkungen zu sechs Bronzereliefs mit Szenen aus Ovid Metamorphosis in Museumm für Kunst und Gewerbe Hamburg”. En: Jahrbuch der Hamburger Kunstsammlungen, 5, pp. 31-52.

Gramberg, Werner (1964): Die Düsseldorfer Skizzenbuch des Guglielmo Della Porta. 3 vols. Berlín.

Jordán de Urriés de la Colina, Javier (2009): La Real Casa del Labrador de Aranjuez. Patrimonio Nacional. Junquera Mato, Juan José (1979): La decoración y el mobiliario de los Palacios de Carlos IV. Madrid.

Kappel, Jutta (1997): "Das Urteil des Paris. Ein Elfenbeinrelief aus dem Umkreis des Giovanni Battista Pozzo nach einer Vorlage von Guglielmo Della Port aim Grünen Gewölbe Dresden”. En: Weltkunst 15, febrero, pp. 280-284.

King, William (1926, reprint 1968): "A relic of Horace Walpole I The cabinet; Longhurst, Margareth. II The ivories. En: Burlington Magazine, enero-junio, pp. 128-129, figs. A-F.

Les Rosset, un atelier jurassien aux temps des Lumières. Con estudio introductorio de Marie-Liesse Pierre. Dole: Musée des Beaux Arts de Dole. 24 nov. 2001-10 feb. 2002.

Longhurst, Vid. King.

Malgouyres, Philippe (2010): Ivoires de la Renaissance et des temps moderns. La collection duj musée du Louvre.

Milet, Ambroise (1904): Anciennes Industries scientifiques et artistiques dieppoises. París.

Arch. esp. arte, LXXXVIII, 351, JULIO-SEPTIEMBRE 2015, 243-262

ISSN: 0004-0428, eISSN: 1988-8511, doi: 10.3989/aearte.2015.15 
Morey, C.R. (1936): Gli oggetti d'avorio e di osso dei Musei Sacro Vaticano. Ciudad del Vaticano.

Pérez de Tudela, Almudena (2001): "Sobre pintura y pintores en El Escorial en el siglo XVI". En: El Monasterio del Escorial y la Pintura, Madrid: Simposium.

Pérez de Tudela, Almudena (2007): "El papel de los embajadores españoles en Roma como agentes artísticos de Felipe II: los hermanos Luis de Requesens y Juan de Zúñiga (1563-1579)”. En: Hernando Sánchez, C. J. (coord.). Roma y España. Un crisol de la Cultura europea en la Edad Moderna. Actas del Congreso Internacional, Real Academia de España en Roma, vol. I, mayo. pp. 391-420.

Raggio, Olga (1983): Cat. 53 en The Vatican Collections. The Papcy and Art, Nueva York, Metropolitan Museum.

Ramos Frenda, Eva María (2009): "Las Duquesas de Parcent. Dos malagueñas en pos de la cultura y el arte”. En: Jábega, mayo-agosto.

Roma di Sisto V. Le Arti e la Cultura. (A cura di Maria Luisa Madonna). Roma, 1993,

Sagrada Biblia. Edició Barcelona, Herder, 1960.

Schmidt, Eike D. (2008a): "Christ in the Counter-Reformation. A signed and dated ivory by Giovanni Antonio Gualterio". En: Storia dell'Arte XIX, 119, 5-20.

Schmidt, Eike D. (2008 b): "Cardinal Ferdinando, Maria Maddalena of Austria and the early History of Ivory Sculpture at the Medici Court". En: Collecting Sculpture in Early Modern Europe (a c. di N. Penny e E.D.Schmidt), Washington, pp. 159-183.

Schmidt, Eike D. (2013): Das Elfenbein der Medici. Münich, Hirmer Verlag.

Sotheby's: Londres, 11 december 1988, $\mathrm{n}^{\circ} 371$; Nueva York, 17 de julio de 2000, nº 59.

Sotheby's: Old Master sculpture and Works of Art, Londres, 10 de julio de 2014.

The Vatican Collections. The Papacy and art (1983): Nueva York. The Metropolitan Museum of Art.

Theurkauff, Christian (1984): Elfenbein. Sammlung Reiner Winkler I. Münich.

Theurkauff, Christian (1986): Nachmittelalterlicher Elfenbein. Die Bildwerke in Elfenbein des 16-19 Jahrhunderts. Berlín. Staatliche Museen Preussischer Kulturbesitz.

Theurkauff, Christian (1994): Elfenbein. Sammlung Reiner Winkler. Band II. (Mit Addenda and Corrigend zu Teil I), Satz.

Trusted, Marjorie (2013): Baroque and later ivories. Victoria and Albert Museum.

Fecha de recepción: 2-VII-2014

Fecha de aceptación: 19-XII-2014

Arch. esp. arte, LXXXVIII, 351, JULIO-SEPTIEMBRE 2015, 243-262 ISSN: 0004-0428, eISSN: 1988-8511, doi: 10.3989/aearte.2015.15 